\title{
Analisis Hubungan Efektifitas Pelatihan Kompetensi Tenaga Kerja Konstruksi Terhadap Level Kirkpatrick
}

\author{
Dwifitra Jumas ${ }^{1}$, Vivi Ariani ${ }^{2}$, Asrini ${ }^{3}$ \\ Fakultas Teknik Sipil dan Perencanaan, Universitas Bung Hatta Padang ${ }^{1,2}$, LPJK Sumbar ${ }^{3}$ \\ Email: dwifitraj@bunghatta.ac.id \\ DOI: http://dx.doi.org/10.31869/rtj.v4i1.2093
}

\begin{abstract}
Abstrak: Pelatihan berbasis kompetensi merupakan pelatihan yang mengacu kepada Standar Kompetensi Kerja Indonesia. Selama kurun waktu 2014 sampai dengan 2015, jumlah pelatihan sumber daya manusia jasa konstruksi Sumatera Barat mengalami peningkatan lebih dari 3 kali lipat dengan jumlah 5 kegiatan pelatihan berbasis kompetensi pada tahun 2014 dan 17 kegiatan pada tahun 2015. Untuk itu, perlu dilakukan evaluasi terhadap efektifitas kegiatan Pelatihan Berbasis Kompetensi yang telah dilaksanakan tersebut, khususnya di Sumatera Barat dengan mempertimbang 3 aspek diatas yaitu knowledge, skill dan attitude. Metode Penelitian dilakukan dengan menggunakan kuesioner sebagai instrumen penelitian. Untuk melihat hubungan antara evaluasi pelatihan empat level Kirkpatrick dengan kompetensi pada bidang yang dilatih dilakukan dengan menggunakan korelasi Bivariat Kendall's Tau pada program SPSS. Dari hasil analisat 43 indikator pada 4 level Kirkpatrick (reaksi, pembelajaran, prilaku dan hasil), 58,1\% indikator yang efektif, sisanya 18 indikator tidak efektif. Sedangkan hubungan indikator yang efektif terhadap 6 kompentensi menunjukan hanya 24\% yang signifikan yaitu H1 (pelatihan mampu merubah cara pandang, cara berfikir, sikap dan prilaku), H5 (pelatihan mampu meningkatkan keterampilan dalam melaksanakan pekerjaan), $H 9$ (pelatihan mampu meningkat-kan dalam membaca gambar dan sketsa) dan $R 2$ (materi yang diberikan sesuai dengan unit kompetensi bidang pelatihan).
\end{abstract}

Kata kunci: Pelatihan berbasis kompetensi, empat level kirkpatrick, evaluasi, efektivitas

\section{PENDAHULUAN}

Industri konstruksi merupakan salah satu sektor yang memainkan peran penting dalam pertumbuhan social-ekonomi dalam suatu negara yang merupakan konstributor utama terhadap PDB suatu Negara. Untuk itu Negara berperan dan bertanggung jawab menyediakan infrastruktur yang diperlukan untuk meningkatkan kualitas kehidupan Negara tersebut. Infrastruktur adalah salah satu prasyarat bagi sektor lain untuk berkembang yang akan memberikan dampak pertumbuhan ekonomi maupun social baik secara langsung atau tidak [8].

Sejak tahun 2015, pemerintah mengalihkan belanja subsidi menjadi belanja produktif, yakni pembangunan infrastruktur, kesehatan, dan pendidikan dengan anggaran infrastruktur terus meningkat dari $\mathrm{Rp} 155$ triliun pada 2014 menjadi sekitar Rp 410 triliun pada tahun 2018 [4]. Agar terciptanya keberhasilan pembangunan infrastruktur ini, maka harus juga diiringi dengan sumber daya manusia (SDM) atau tenaga kerja di bidang konstruksi. Untuk itu, perkembangan teknologi sekarang ini, harus dikenali, dipelajari dan diikuti oleh SDM konstruksi Indonesia.

Dalam menghadapi tantangan diatas perlu dilakukan pembinaan dan pemberdayaan sumber daya manusia konstruksi melalui pelatihan. Pendekatan pelatihan cukup efektif dalam membantu peserta pelatihan mencapai kompetensi yang telah ditetapkan dalam suatu jabatan kerja tertentu yaitu melalui pelatihan berbasis kompetensi [5]. Pelatihan berbasis kompetensi merupakan pelatihan yang mengacu kepada Standar Kompetensi Kerja Indonesia. Kurikulum, silabus, materi pelatihan dan metode pelatihan yang disajikan dalam proses pembelajaran merupakan penjabaran dari setiap unit kompetensi, elemen kompetensi dan kriteria unjuk kerja. Pelatihan berbasis kompetensi juga merupakan proses sistematis yang diharapkan dapat mengubah pengetahuan, keterampilan dan sikap kerja seseorang [7]. Tahapan pelaksanaan kegiatan pelatihan berbasis kompetensi dimulai dari persiapan pelatihan, pelaksanaan pelatihan, penerbitan sertifikat pelatihan dan evaluasi dan pelaporan penyelenggaraan pelatihan.

Terbitnya peraturan menteri pekerjaan umum dan perumahan rakyat nomor 
24/PRT/M/2014 tentang Pedoman Pelatihan Berbasis Kompetensi Bidang Jasa Konstruksi, merupakan upaya tegas pemerintah dalam melakukan peningkatan kemampuan SDM konstruksi yang berkelanjutan agar menghasilkan SDM yang produktif dan kompeten, baik yang dilakukan oleh pemerintah pusat melalui Balai Pelatihan Konstruksi Wilayah, maupun melalui pemerintah setiap propinsi yang ada di Indonesia.

Dalam peraturan menteri diatas, disebutkan bahwa pelatihan berbasis kompetensi adalah pelatihan kerja yang menitikberatkan pada penguasaan kemampuan kerja yang mencakup pengetahuan (knowledge), keterampilan (skill), dan sikap kerja (attitude) sesuai dengan standar dan persyaratan yang ditetapkan di tempat kerja.

Selama kurun waktu 2014 sampai dengan 2015, jumlah pelatihan sumber daya manusia jasa konstruksi Sumatera Barat mengalami peningkatan lebih dari 3 (tiga) kali lipat dengan jumlah 5 kegiatan pelatihan berbasis kompetensi pada tahun 2014 dan 17 kegiatan pada tahun 2015 [1]. Sedangkan berdasarkan usulan pendanaan untuk kegiatan Pelatihan Berbasis Kompetensi di propinsi Sumatera Barat tahun 2015, untuk satu kegiatan Pelatihan Berbasis Kompetensi memerlukan pendanaan sebesar Rp. 150.000.000,- (seratus lima puluh juta rupiah).

Dengan melihat jumlah kegiatan pelatihan berbasis kompetensi yang semakin meningkat tersebut, tentunya kebutuhan pendanaan serta jumlah kegiatan pelatihan berbasis kompetensi juga semakin meningkat. Untuk itu, perlu dilakukan evaluasi terhadap efektifitas kegiatan Pelatihan Berbasis Kompetensi yang telah dilaksanakan tersebut, khususnya di Sumatera Barat dengan mempertimbang 3 aspek diatas yaitu knowledge, skill dan attitude dari peserta pelatihan.

\section{METODE PENELITIAN}

Survey lapangan menggunakan kuisioner sebagai instrumen penelitian untuk data primer. Perancangan kuesioner evaluasi empat level Kirkpatrick dilakukan berdasarkan karakteristik setiap level evaluasi Kirkpatrick dan juga disesuaikan dengan karakteristik responden yang terlibat pada setiap level evaluasi. Pengumpulan data dilakukan berdasarkan data primer dan data sekunder. Data primer merupakan data yang dikumpulkan melalui kusioner sedangkan data sekunder merupakan data-data yang dikumpulkan berdasarkan laporan kegiatan pelatihan SDM jasa konstruksi Sumatera Barat berbasis kompetensi yang diadakan oleh LPJK Sumbar dari tahun 2017 sampai dengan 2018.

Pengolahan data yang didapat pada penelitian dilakukan secara statistik menggunakan pengujian validitas dan reliabilitas data untuk setiap empat level evaluasi. Uji validitas dan reliabilitas pada setiap indicator pada 4 level variable instrumen penelitian dilakukan menggunakan program SPSS dengan metoda AlphaCronbach untuk setiap level variabel instrumen penelitian. Indikator dinyatakan valid jika $r$ hitung > nilai $r$ tabel untuk $\mathrm{N}$ sampel 35 dengan taraf signifikan 5\% dan 1 $\%$. Sedangkan indikator dinyatakan valid jika nilai Alpha-Cronbach > 0.70 .

Untuk uji normalitas data dilakukan untuk melihat apakah data yang diperoleh terdistribusi normal atau tidak. Distribusi data diperlukan untuk menentukan kategori data berdasarkan nilai cut off poin data. Variabel dengan data yang terdistribusi normal menggunakan nilai mean sebagan cut off poin. Sementara untuk variabel dengan data tidak terdistribusi normal menggunakan median sebagai cut off point

Untuk melihat hubungan antara evaluasi pelatihan empat level Kirkpatrick dengan kompetensi pada bidang yang dilatih dilakukan dengan nilai koefisien korelasi setiap variabel dengan menggunakan analisis korelasi Bivariat Kendall's Tau pada program SPSS.

\section{HASIL DAN PEMBAHASAN \\ Data dan Analisis Responden Penelitian}

Data karakteristik responden didapatkan dari kuesioner yang disebar pada kegiatan pelatihan tenaga kerja konstruksi yang diadakan oleh LPJK Sumbar dari Tahun 2017-20185 sesuai dengan jumlah sampel yang telah ditetapkan yakni sebanyak 64 orang. Dari total 64 orang responden, distribusi berdasarkan umur, responden dominan berada pada kelompok umur $20 \mathrm{~s} / \mathrm{d}$ 30 tahun sebanyak 56,3\% yaitu 36 orang. Sedangkan berdasarkan jenjang pendidikan responden, yang paling banyak adalah 
pendidikan SMA sebanyak 48,4\% dan diikuti oleh pendidikan diploma sebanyak $20,3 \%$. Untuk pengalaman lama bekerja responden yang mengikuti pelatihan kompetensi paling banyak adalah bekerja kurang dari 1 tahun $(40,6 \%)$, dan dikuti oleh lebih dari 5 tahun sebanyak 22\%. Untuk lebih lengkapnya mengenai data responden dapat dilihat pada Gambar 3 dibawah ini.

\section{Evaluasi 4 Level Kirkpatrick}

Benchmarking evaluasi pelatihan menggunakan model evaluasi empat level Kirkpatrick dan dilakukan dengan menggunakan contoh karakteristik variabel evaluasi setiap level menurut Noe [3], studi kasus dalam Kirkpatrick [3] maupun karakteristik variabel evaluasi yang telah digunakan pada penelitian sejenis yang pernah dilakukan sebelumnya [6]. Seperti pada Tabel dibawah ini.

Tabel 1: Level Reaksi

\begin{tabular}{|c|c|}
\hline No & Indikator \\
\hline R1 & $\begin{array}{l}\text { Semua materi yang diberikan sesuai } \\
\text { dengan bidang pelatihan. }\end{array}$ \\
\hline R2 & $\begin{array}{l}\text { Materi yang diberikan sesuai dengan unit } \\
\text { kompetensi bidang pelatihan. }\end{array}$ \\
\hline R3 & $\begin{array}{l}\text { Instruktur menguasai materi pelatihan } \\
\text { yang diberikan dan mampu menjawab } \\
\text { pertanyaan dari peserta dengan jelas. }\end{array}$ \\
\hline R4 & $\begin{array}{l}\text { Instruktur menyampaikan materi secara } \\
\text { komunikatif, jelas dan sistematis. }\end{array}$ \\
\hline R5 & $\begin{array}{l}\text { Instruktur mampu memotivasi peserta } \\
\text { dalam mengikuti kegiatan pelatihan } \\
\text { sesuai materi yang disampaikan. }\end{array}$ \\
\hline R6 & $\begin{array}{l}\text { Instruktur mampu mengajak peserta } \\
\text { untuk aktif berdiskusi pada setiap materi } \\
\text { pelatihan. }\end{array}$ \\
\hline R7 & $\begin{array}{l}\text { Tugas/ latihan pada akhir sesi kegiatan } \\
\text { diberikan agar peserta lebih mendalami } \\
\text { materi yang telah diberikan. }\end{array}$ \\
\hline $\mathrm{R} 8$ & $\begin{array}{lll}\text { Kondisi waktu pelatihan tidak } \\
\text { mengganggu } & \text { kegiatan Kerja }\end{array}$ \\
\hline R9 & $\begin{array}{l}\text { Waktu yang disediakan pada setiap } \\
\text { materi pelatihan sudah cukup }\end{array}$ \\
\hline R10 & $\begin{array}{l}\text { Kegiatan pelatihan sesuai dengan jadwal } \\
\text { yang telah diberikan. }\end{array}$ \\
\hline R11 & $\begin{array}{l}\text { Kapasitas ruangan mampu menampung } \\
\text { seluruh peserta pelatihan }\end{array}$ \\
\hline R12 & $\begin{array}{l}\text { Alat peraga/media presentasi yang } \\
\text { digunakan saat menyampaikan materi } \\
\text { membantu peserta dalam memahami } \\
\text { isi materi. }\end{array}$ \\
\hline
\end{tabular}

\begin{tabular}{ll}
\hline R13 & $\begin{array}{l}\text { Modul/handout pelatihan membantu } \\
\text { peserta dalam memahami materi yang } \\
\text { disampaikan }\end{array}$ \\
\hline R14 & $\begin{array}{l}\text { Anda puas dengan konsumsi yang } \\
\text { disediakan. }\end{array}$ \\
\hline R15 & pelatihan yang anda ikuti menyenangkan. \\
\hline R16 & $\begin{array}{l}\text { Pelatihan yang diikuti memberikan nilai } \\
\text { praktis }\end{array}$ \\
\hline R17 & $\begin{array}{l}\text { Anda termotivasi untuk menerapkan } \\
\text { materi pelatihan }\end{array}$ \\
\hline R18 & $\begin{array}{l}\text { Respon panitia dalam melayani peserta } \\
\text { sangat baik. }\end{array}$ \\
\hline R19 & $\begin{array}{l}\text { Informasi yang diberikan penyelenggara } \\
\text { kegiatan pelatihan sangat baik. }\end{array}$ \\
\hline R20 & $\begin{array}{l}\text { Kegiatan pelatihan yang diikuti sangat } \\
\text { anda butuhkan. }\end{array}$ \\
\hline R21 & $\begin{array}{l}\text { Secara keseluruhan, bagaimana menurut } \\
\text { anda kegiatan pelatihan yang anda ikuti }\end{array}$ \\
\hline
\end{tabular}

Pada tingkat reaksi, terdapat 21 butir indikator yang akan menggambarkan tingkat kepuasan responden terhadap pelatihan. Pelatihan dinilai efektif jika tingkat reaksi yang menyatakan rataan skor kepuasan responden berada di atas nilai cut off poin4. Pada Tabel 1, R3, R4, R5, R6, R8, R10, R12, R13 adalah indikator yang mempunyai nilai cut off poin dibawah 4.

Tabel 2: Level Pembelajaran (Learning)

\begin{tabular}{l|l}
\hline No & Indikator \\
\hline L1 & $\begin{array}{l}\text { Materi Komunikasi dan Kerjasama Di } \\
\text { Lingkungan Kerja }\end{array}$ \\
\hline L2 & Materi Membuat Jadwal Kerja \\
\hline L3 & $\begin{array}{l}\text { Materi Keselamatan dan Kesehatan Kerja } \\
\text { dan Lingkungan (K3-L) }\end{array}$ \\
\hline L4 & $\begin{array}{l}\text { Materi membuat laporan pelaksanaan } \\
\text { pekerjaan }\end{array}$ \\
\hline L5 & $\begin{array}{l}\text { Materi khusus yang sesuai dengan } \\
\text { pelatihan yang di ikuti }\end{array}$ \\
\hline L6 & $\begin{array}{l}\text { Sejauh mana anda merasa telah belajar } \\
\text { dari program pelatihan. }\end{array}$ \\
\hline
\end{tabular}

Pada tingkat pembelajaran, terdapat 6 butir indikator yang akan menggambarkan tingkat kepuasan responden terhadap pelatihan. Pelatihan dinilai efektif jika tingkat reaksi yang menyatakan rataan skor kepuasan responden berada di atas nilai cut off poin4. Pada Tabel 2, L1, L2 dan L3 adalah indikator yang nilai cut off point dibawah 4 yaitu 3.92; 3.81 dan 3.23.

Tabel 3: Level Prilaku (Behaviour) 


\section{No DAFTAR PERNYATAAN}

B1 Setelah mengikuti pelatihan anda menjadi lebih disiplin.

Setelah mengikuti pelatihan anda menjadi

B2 lebih bertanggung jawab dalam semua hal.

B3 Setelah mengikuti pelatihan anda menjadi lebih mandiri

B4 Setelah mengikuti pelatihan anda menjadi lebih termotivasi dalam bekerja

Setelah mengikuti pelatihan anda menjadi

B5 lebih rapi dalam menyimpan peralatan gambar yang telah digunakan.

Pada tingkat prilaku, terdapat 5 butir indikator yang akan menggambarkan tingkat kepuasan responden terhadap pelatihan. Pelatihan dinilai efektif jika tingkat reaksi yang menyatakan rataan skor kepuasan responden berada di atas nilai cut off poin 4 . Pada Tabel 3, B1, B2 dan B3 adalah indikator yang nilai cut off point dibawah 4 yaitu 3.95; 3.94 dan 3.95.

Tabel 4: Level Hasil

\section{No DAFTAR PERNYATAAN}

H1 Pelatihan mampu merubah cara pandang, cara berfikir, sikap dan perilaku anda

H2 Mempraktekan materi pelatihan pada pekerjaan anda.

Pelatihan sangat membantu anda dalam

H3 melaksanakan pekerjaan dengan lebih baik.

Pelatihan sangat membantu anda

H4 menyelesaikan pekerjaan dengan hasil memuaskan.

Pelatihan mampu meningkatkan

H5 keterampilan anda dalam melaksanakan pekerjaan.

H6

Pelatihan membantu anda untuk mengatur dan memanfaatkan waktu dengan baik.

\begin{tabular}{llr}
\hline & $\begin{array}{l}\text { Pelatihan mampu meningkatkan } \\
\text { keterampilan anda menentukan keperluan } \\
\text { alat dan bahan yang digunakan untuk } \\
\text { melaksanakan pekerjaan. }\end{array}$ \\
\hline H8 & $\begin{array}{l}\text { Pelatihan Mampu meningkatkan } \\
\text { keterampilan anda dalam membuat jadwal } \\
\text { kerja }\end{array}$ \\
\hline H9 & $\begin{array}{l}\text { Pelatihan Mampu meningkatkan anda } \\
\text { dalam membaca gambar dan sketsa. }\end{array}$ \\
\hline
\end{tabular}

\begin{tabular}{ll}
\hline H10 & $\begin{array}{l}\text { Pelatihan mampu meningkatkan } \\
\text { keterampilan anda dalam membuat } \\
\text { laporan hasil pekerjaan. }\end{array}$ \\
H11 & $\begin{array}{l}\text { Secara keseluruhan, pelatihan sangat } \\
\text { bermanfaat dalam menunjang pekerjaan } \\
\text { anda }\end{array}$ \\
\hline
\end{tabular}

Pada tingkat hasil, terdapat 11 butir indikator yang akan menggambarkan tingkat kepuasan responden terhadap pelatihan. Pelatihan dinilai efektif jika tingkat reaksi yang menyatakan rataan skor kepuasan responden berada di atas nilai cut off poin 4 . Pada Tabel 4, H2, H4, H6 dan H10 adalah indikator yang nilai cut off point dibawah 4 .

\section{Analisis Efektifitas Pelatihan terhadap Kompetensi}

Dari semua indikator yang ada pada setiap level Kirkpatrick, dilakukan analisis hubungan terhadap 5 kompetensi yaitu knowledge (K1 dan $\mathrm{K} 2$ ), skill ( $\mathrm{S} 1$ dan $\mathrm{S} 2$ ) dan attitude (A1 dan A2). Untuk mengambarkan hubungan yang erat antara kopetensi dan indikator yang efektif dapat dilihat pada konsistensi data terhadap prediksi model persamaan yang ditunjukkan dengan nilai signifikan dari nilai chi-squareberdasarkan Pearson's dan Deviance. Data dikatakan konsisten dengan prediksi model persamaan jika nilai signifikan $>0.05$. Sedangkan untuk hasil indikator kompetensinya dapat dilihat pada gambar dibawah ini untuk setiap masingmasing kompetensi.

Tabel 5:signifikan dari nilai chi-square $\mathrm{K} 1$

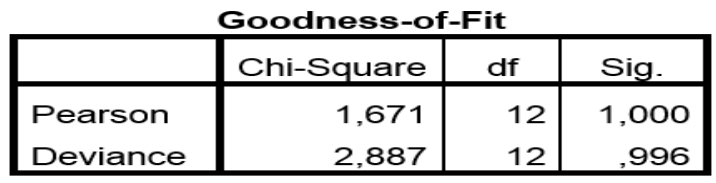

Link function: Complementary Log-log. 


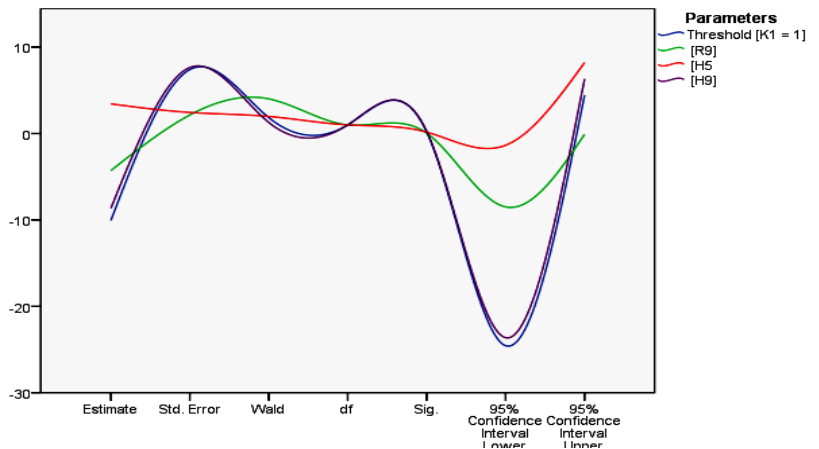

Gambar 1. Pengaruh indikator evaluasi pelatihan terhadap Kompetensi K1

Dari Gambar 1, indikator kompetensi knowledgebisa mendiagnosa gambar dan sketsa (K1) 87,6\% dipengaruhi oleh indikator R9,H5, dan H9 secara kumulatif. Artinya indikator waktu yang disediakan untuk materi (R9), pelatihan mampu meningkatkan keterampilan dalam melaksanakan pekerjaan (H5) dan meningkatkan dalam membaca gambar dan sketsa (H9) mempunyai hubungan yang erat dengan kompetensi K1. Tetapi karena R9 tidak efektif pada level reaksi Kirkpatrick, maka hanya H5 dan H9 saja mempunyai hubungan erat pada $\mathrm{K} 1$.

Tabel 6:signifikan dari nilai chi-square K2

\section{Goodness-of-Fit}

\begin{tabular}{|l|l|l|l|}
\hline & Chi-Square & df & Sig. \\
\hline Pearson &, 447 & 7 & 1,000 \\
Deviance &, 870 & 7 &, 997 \\
\hline
\end{tabular}

Link function: Complementary Log-log.

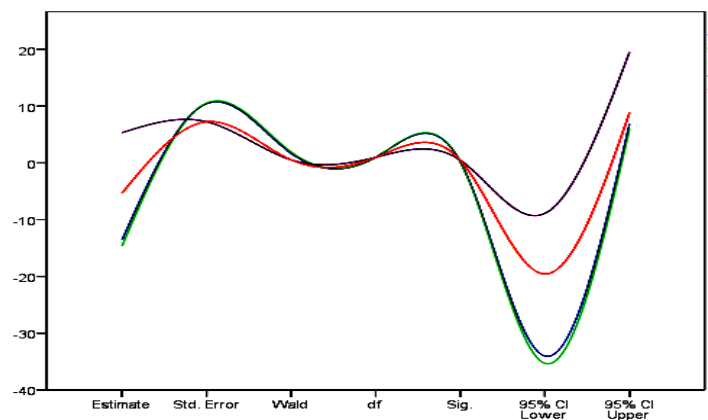

- Parameters - hiresnold $K K_{2=1}$ kirkpatrick

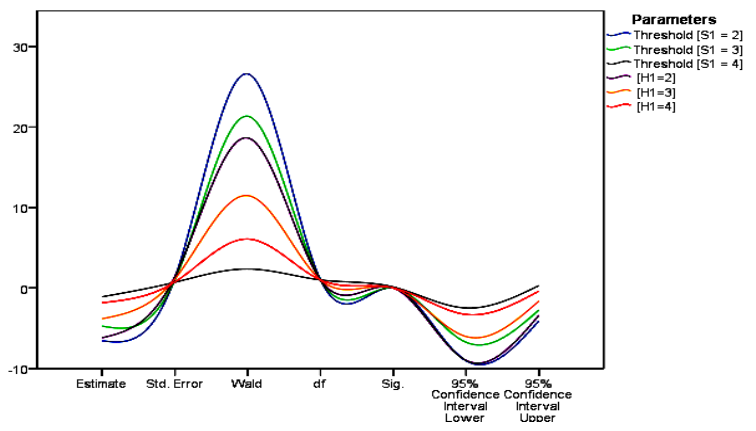

Gambar 3. Pengaruh indikator evaluasi pelatihan terhadap Kompetensi S1

Dari Gambar 3, indikator kompetensi skill mampu melaksanakan prosedur keselamatan dan kesehatan kerja serta lingkungan di tempat kerja (S1),56,8\% dipengaruhi oleh satu-satunya indikator H1 secara kumulatif.Indikator pelatihan mampu merubah cara pandang, cara berfikir, sikap dan perilaku (H1) adalah efektif pada level hasil

Tabel 8: signifikan dari nilai chi-square S2 Goodness-of-Fit

\begin{tabular}{|l|l|l|l|}
\hline & Chi-Square & df & Sig. \\
\hline Pearson & 4.161 & 8 & .842 \\
Deviance & 6.658 & 8 & .574 \\
\hline
\end{tabular}

Link function: Complementary Log-log.

Gambar 2. Pengaruh indikator evaluasi

pelatihan terhadap Kompetensi K2

Dari Gambar 2, indikator kompetensi knowledge bisa mengidentifikasi alat dan bahan yang diperlukan (K2) 84,8\% dipengaruhi oleh indikator R9, L1, L2 dan H1 secara kumulatif. Dari 4 indikator yang mempunyai hubungan erat dengan $\mathrm{K} 2$, hanya satu indikator yang efektif terhadap level 


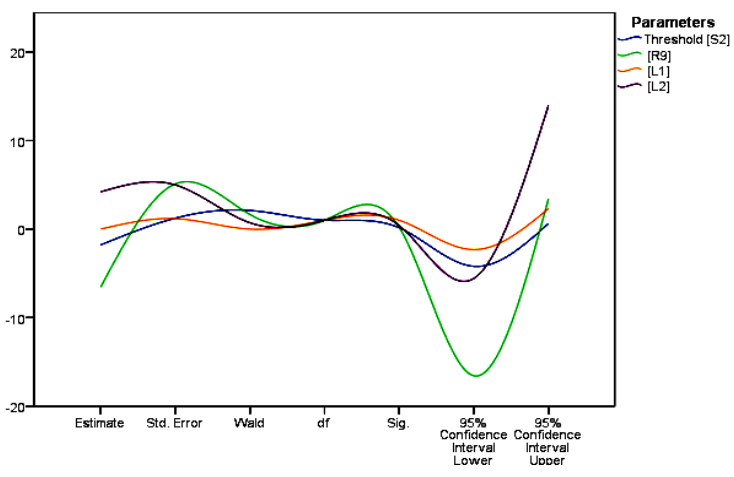

Gambar 4. Pengaruh indikator evaluasi pelatihan terhadap Kompetensi S2

Dari Gambar 4, indikator kompetensi skill mampu melakukan pengambaran (S2)90,3\% dipengaruhi oleh indikator R9, L1 dan L2 secara kumulatif. Dari ketiga indikator tersebut, tidak ada satupun indikator yang efektif terhadap level Kirkpatrick.

Tabel 9: signifikan dari nilai chi-square A1

\section{Goodness-of-Fit}

\begin{tabular}{|l|l|l|l|}
\hline & $\begin{array}{l}\text { Chi- } \\
\text { Square }\end{array}$ & df & Sig. \\
\hline $\begin{array}{l}\text { Pearson } \\
\text { Devian } \\
\text { ce }\end{array}$ & 9,632 & 43 & 1,000 \\
\hline
\end{tabular}

Link function: Complementary Log-log.

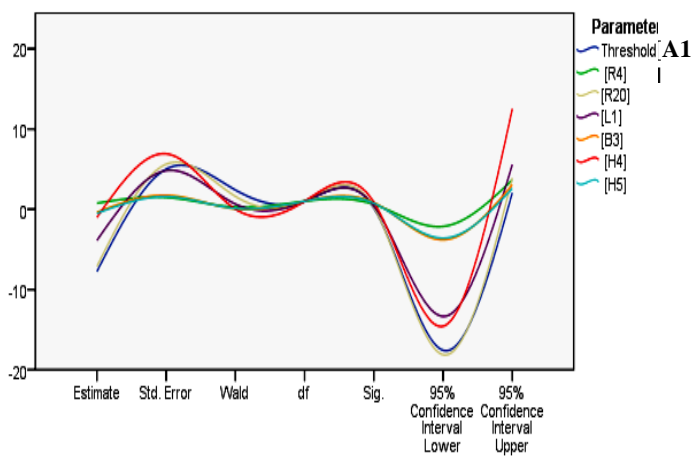

Gambar 5. Pengaruh indikator evaluasi pelatihan terhadap Kompetensi A1

Dari Gambar 5, indikator kompetensi attitude yaitu menyimpan/merapikan gambar dan peralatan yang telah selesai digunakan (A1), 84,8\% dipengaruhi oleh indikator R4, R20, L1, B3, H4 dan H5 secara kumulatif. Dari 6 indikator yang mempunyai hubungan erat dengan $\mathrm{A} 1$, hanya dua indikator yang efektif terhadap level Kirkpatrick yaitu kegiatan pelatihan yang dikuti sangat dibutuhkan (R20) dan mampu meningkatkan keterampilan dalam melaksanakan pekerjaan
(H5). Sedangkan indikator R4, L1, B3 dan H4 tidak efektif terhadap level Kirkpatrick.

Tabel 10: signifikan dari nilai chi-square A2

Goodness-of-Fit
\begin{tabular}{|l|l|l|l|}
\hline & $\begin{array}{l}\text { Chi- } \\
\text { Square }\end{array}$ & df & Sig. \\
\hline $\begin{array}{l}\text { Pearson } \\
\text { Devian } \\
\text { ce }\end{array}$ & 0,642 & 43 &, 993 \\
\hline
\end{tabular}

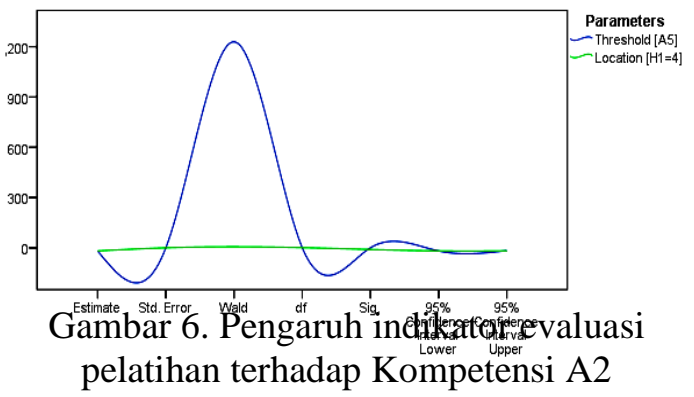

Dari Gambar 6, indikator kompetensi attitude mampu mengadakan bimbingan teknis pada mitra kerja (A2), 41,7\% dipengaruhi oleh satu-satunya indikator $\mathrm{H} 1$ secara kumulatif.Indikator pelatihan mampu merubah cara pandang, cara berfikir, sikap dan perilaku (H1) adalah efektif pada level hasil kirkpatrick.

\section{PENUTUP}

Dari 43 indikator pada 4 level Kirkpatrick (reaksi, pembelajaran, prilaku dan hasil), terdapat 58,1\% indikator yang efektif, sisanya 18 indikator tidak efektif. Hasil analis setelah dilakukan evaluasi hubungan terhadap indikator yang efektif pada 6 kompentensi menunjukan hanya $16 \%$ yang signifikan. Indikator H1 (pelatihan mampu merubah cara pandang, cara berfikir, sikap dan perilaku) merupakan indikator yang mempunyai hubungan dengan 3 kompetensi yaitu K2, S2 dan A2.

Indikator H5 (pelatihan mampu meningkatkan keterampilan dalam melaksanakan pekerjaan mempunyai hubungan signifikan terhadap 2 kompetensi yaitu K1 dan A1.

Sedangan indikator H9 (pelatihan mampu meningkat-kan dalam membaca gambar dan sketsa) dan indikator R2 (materi yang diberikan sesuai dengan unit kompetensi bidang pelatihan) hanya mempunyai hubungan 
signifikan terhadap 1 kompetensi yaitu K1 dan A2.

Untuk kompetensi S2 tidak mempunyai hubungan signifikan satu pun terhadap indikator yang efektif. Secara garis besar, dapat disimpulkan bahwa pelatihan kompetensi tenaga kerja yang dilakukan di Sumatera Barat tahun 2017 sampai tahun 2018 masih kurang efektif.

\section{DAFTAR PUSTAKA}

[1] Asrini, Zaidir, Zuherna Mizwar. (2017). Evaluasi Efektifitas Pelatihan Sumber Daya Manusia Berbasis Kompetensi Untuk Peningkatan Daya Saing Jasa Konstruksi Sumatera Barat. Jurnal Program Pascasarjana Universitas Bung Hatta, 9 (3),

[2] Abu Ahmadi dan Widodo Supriyono. Psikologi Belajar. Jakarta: Rineka Cipta. (2013)

[3] Badu, Q., S. (2013). The Implementation of Kirkpatrick's Evaluation Model in the Learning of Initial Value and Boundary Condition Problems.International Journal of Learning and Development, 3(5).

[4] Internet Website of Kementrian Keuangan (Kemenkeu) Republik Indonesia. Ini Capaian Pembangunan Infrastrktur Indonesia, Oktober, 24, 2018. (https://www.kemenkeu.go.id)

[5] Kodri, I., Fitriani, H., \& Juliantina, I. (2018). Analisa Pengaruh Pelatihan dan Sertifikasi terhadap Produktivitas Pekerja. Media Komunikasi teknik Sipil, 24(1), 9-19

[6] Lin, Y-C., Chen, S-C., \& Chuang, H-T. (2011).The Effect of Organizational Commitment on Employee Reactions to Educational Training: An Evaluation using the Kirkpatrick Four-level Model. Internasional Journal of Management, 28(3), 926-934

[7] Peraturan Menteri Pekerjaan Umum dan Perumahan Rakyat Nomor 24/PRT/M/2014 tentang Pedoman Pelatihan Berbasis Kompetensi Bidang Jasa Konstruksi.

[8] Wasilan \& Noor, Akhmad. (2015). Peranan Infrastruktur terhadap Pertumbuhan Ekonomi dan Implikasi terhadap Kebijakan Pembangunan di Kota Samarinda. Mimbar,31 (2), 359-366 